\title{
TYMPANOPLASTY WITH SEPTAL CARTILAGE AND CORTICAL MASTOID BONE IN CHOLESTEATOMA PATIENTS
}

\author{
T. Biram Singh ${ }^{1}$, N. Devakanta Singh ${ }^{2}$, N. Lungleng 3 \\ ${ }^{1}$ Senior Resident, Department of ENT, JNIMS, Porompat. \\ ${ }^{2}$ Assistant Professor, Department of ENT, JNIMS, Porompat. \\ ${ }^{3}$ Assistant Professor, Department of ENT, JNIMS, Porompat.
}

\section{ABSTRACT}

\section{OBJECTIVE}

This study was conducted to find out the ideal graft between septal cartilage and cortical mastoid bone in Farrior's type 3 tympanoplasty in cholesteatoma patients in terms of hearing improvement, graft status and recurrence rate of the disease after canal wall down mastoidectomy.

\section{METHODS}

This randomized controlled trial was conducted in a tertiary care centre and the procedure and data collections were carried out for one and a half calendar year with effect from September 2007 and each case was followed up for 6 months. The data were entered and calculated statistically using SPSS16 for windows.

\section{RESULTS}

The study shows significant hearing improvement in both the groups. The tympanoplasty type 3 with cortical mastoid bone had air bone gap less than $20 \mathrm{~dB}$ in $40 \%$ of patients. In septal cartilage, tympanoplasty group air bone gap less than $20 \mathrm{~dB}$ was observed in $36.4 \%$. Retraction of graft developed in $1(2.4 \%)$ out of 20 patients among cortical mastoid bone tympanoplasty group. Among 22 patients of septal cartilage tympanoplasty type 3,2(4.8\%) patients had cartilage resorption and 3(7.1\%) had graft displacement. Of the total 42 patients, $2(4.8 \%)$ developed recurrence of the disease.

\section{CONCLUSION}

Cholesteatoma management is controversial. Canal wall down mastoidectomy can reduce the recurrence of disease. The cortical mastoid bone and septal cartilage grafts can provide hearing improvement after tympanoplasty type 3 . There is no significant difference in hearing improvement between the two grafts.

\section{KEYWORDS}

Tympanoplasty, Cholesteatoma, Decibel (dB), Airbone Gap (ABG).

HOW TO CITE THIS ARTICLE: Singh TB, Singh ND, Lungleng N. "Tympanoplasty with septal cartilage and cortical mastoid bone in cholesteatoma patients." Journal of Evolution of Medical and Dental Sciences 2015; Vol. 4, Issue 103, December 24; Page: $16852-16854$, DOI: $10.14260 /$ jemds/2015/2533

\section{INTRODUCTION}

Tympanoplasty is an operation performed to eradicate disease from the middle ear and to reconstruct, if possible the hearing mechanism. ${ }^{1}$ the modern concepts and techniques of tympanoplasty came into being due to pioneering works of Wullstein, Zollner and Heerrman.2

Different types of autologous, homologous and synthetic grafts can be used for tympanoplasty. Homologous grafts, though once popular are abandoned due to risk of transmission of HIV, Creutzfeldt Jacob disease. ${ }^{3}$ Autogenous ossicles are frequently used for tympanoplasty. However, they were found to be associated with increased risk for postoperative infection and residual cholesteatoma. ${ }^{4}$ The use of mastoid cortical bone and nasal septal cartilage in the reconstructive surgery of the middle ear was introduced by Hugh and Jensen respectively. ${ }^{5}$ Septal cartilage has less chance of cartilage reabsorption compared to conchal cartilage. ${ }^{6}$ However, conchal cartilage has the advantage of avoiding another incision.

Financial or Other, Competing Interest: None.

Submission 15-12-2015, Peer Review 16-12-2015,

Acceptance 18-12-2015, Published 23-12-2015.

Corresponding Author:

Dr. T. Biram Singh,

Senior Resident Department of ENT,

JNIMS, Porompat,

Imphal-795004.

E-mail: birtk123@gmail.com

DOI:10.14260/jemds/2015/2533
The synthetic PORP and TORP are costly and not all the patients can afford it.

It is in the light of above controversy to find the ideal graft material for tympanoplasty that this study intends to find out better graft between the use of nasal septal cartilage and cortical mastoid bone in Farrior's type 3 tympanoplasty after canal wall down mastoidectomy in terms of hearing improvements and graft status.

\section{MATERIAL AND METHODS}

This randomized controlled trial was conducted on patients older than 15 years and younger than 65 years with cholesteatoma at a Tertiary Care Centre. Patients after canal wall down mastoidectomy surgery for cholesteatoma were reconstructed using septal cartilage and cortical mastoid bone grafts as strut in between temporalis fascia graft and stapes suprastructure. Cavity obliteration technique was used with pedicled flap and meatoplasty was done in all the patients.

The pre-operative audiometry were compared with audiometric outcome after 6 months of surgery. The status of the graft and recurrence of the disease are noted.

Patients with extensive cholesteatoma with moderate to profound sensorineural hearing loss, labyrinthitis and intracranial complications are excluded. Patients with systemic diseases are also excluded.

\section{RESULTS}

Of the 47 patients studied, 5 patients were lost to followup and $42(89.4 \%)$ patients were available for analysis; 20 patients are 
male. Maximum cases of cholesteatoma were seen in the age group of 21-30 years, which constitutes $38.1 \%$ of the cases; 22 patients underwent cartilage tympanoplasty with septal cartilage and 20 patients had tympanoplasty with cortical mastoid bone.

\begin{tabular}{|c|c|c|c|}
\hline Mean Audiogram & Number of Patients & Mean (deciBel) & Standard Deviation (deciBel) \\
\hline Pre-operative Air-Bone Gap & 20 & 39.04 & 8.06 \\
\hline Post-operative Air Bone Gap (6 months) & 20 & 22.47 & 10.07 \\
\hline Table 1: Pre-operative and post-operative audiogram of tympanoplasty with cortical mastoid bone (n=20) \\
\hline
\end{tabular}

After tympanoplasty with cortical mastoid bone, the mean pre-operative air bone gap was $39.04 \pm 8.06 \mathrm{~dB}$ and post-operative mean air bone gap was $22.47 \pm 10.07 \mathrm{~dB}$ suggesting significant improvement of hearing $(\mathrm{p}=<0.001)$.

\begin{tabular}{|c|c|c|c|}
\hline Mean Audiogram & Number of Patients & Mean (deciBel) & Standard deviation (deciBel) \\
\hline Pre-operative Air Bone Gap & 22 & 39.87 & 7.4 \\
\hline $\begin{array}{c}\text { Post-operative Air Bone Gap (6 } \\
\text { months) }\end{array}$ & 22 & 22.18 & 7.9 \\
\hline \multicolumn{2}{|c|}{ Table 2: Pre-operative and post-operative audiogram of Tympanoplasty with Septal cartilage (n=22) } \\
\hline
\end{tabular}

After tympanoplasty using nasal septal cartilage, the mean pre-operative air bone gap of 22 patients are $39.87 \pm 7.4 \mathrm{~dB}$ and postoperative mean air bone gap was $22.18 \pm 7.9 \mathrm{~dB}$ suggesting significant improvement $(\mathrm{p}=<0.001)$.

\begin{tabular}{|c|c|c|c|c|}
\hline $\begin{array}{c}\text { Hearing Loss } \\
\text { (deciBel) }\end{array}$ & Frequency & Percent & Valid Percent & Cumulative Percent \\
\hline $10-20$ & 8 & 40 & 40 & 40 \\
\hline $21-30$ & 5 & 25 & 25 & 65 \\
\hline $31-40$ & 7 & 35 & 35 & 100.0 \\
\hline Total & 20 & 100 & 100 & \\
\hline Table 3: Post-operative Air Bone gap range of Tympanoplasty with Cortical mastoid bone (n=20)
\end{tabular}

After tympanoplasty using cortical mastoid bone, $40 \%$ of patients had air bone gap less than $20 \mathrm{~dB}$ and $65 \%$ of patients have air bone gap less than $30 \mathrm{~dB}$ and all the patients have air bone gap less than $40 \mathrm{~dB}$.

\begin{tabular}{|c|c|c|c|c|}
\hline Hearing Loss (deciBel) & Frequency & Percent & Valid Percent & Cumulative Percent \\
\hline $10-20$ & 8 & 36.4 & 36.4 & 36.5 \\
\hline $21-30$ & 11 & 50 & 50 & 86.4 \\
\hline $31-40$ & 1 & 4.5 & 4.5 & 90.9 \\
\hline $40-50$ & 2 & 9.1 & 9.1 & 100 \\
\hline \multicolumn{2}{|r|}{ Table 4: Post-operative air bone gap range of Tympanoplasty with Nasal Septal Cartilage (n=22) } \\
\hline
\end{tabular}

Out of 22 patients who had tympanoplasty with septal cartilage, $36.4 \%$ of the patients had air bone gap less than $20 \mathrm{~dB}$ and $86.4 \%$ of patients had air bone gap less than $30 \mathrm{~dB} ; 90.9 \%$ of patients had air bone gap less than $50 \mathrm{~dB} ; 2$ patients however have air bone gap more than $40 \mathrm{~dB}$.

\begin{tabular}{|c|c|c|c|c|}
\hline Complications & $\begin{array}{c}\text { Tympanoplasty with cortical } \\
\text { bone }\end{array}$ & $\begin{array}{c}\text { Tympanoplasty with } \\
\text { cartilage }\end{array}$ & Total & Percent \\
\hline Graft displacement & 0 & 3 & 3 & 7.1 \\
\hline Graft resorption & 0 & 2 & 2 & 4.8 \\
\hline Postero-superior retraction & 1 & 0 & 1 & 2.4 \\
\hline \multicolumn{2}{|c|}{ Table 5: Graft status and recurrence after surgery (n=42) } & 2 & 4.8 \\
\hline
\end{tabular}

Of the 42 patients, who had undergone tympanoplasty, 3(7.1\%) patients had graft displacement. Graft resorption was seen in $2(4.8 \%)$ patients and $1(2.4 \%)$ patient with cortical mastoid bone tympanoplasty had postero-superior retraction; $2(4.8 \%)$ patients had recurrence of Cholesteatoma.

\section{DISCUSSION}

Much controversy exists on the choice of grafts for reconstruction after Cholesteatoma surgery. Septal cartilage and cortical mastoid bone are easily available autologous graft, which can be modified and used in tympanoplasty with high graft uptake rate. ${ }^{7}$

There was significant hearing improvement from preoperative air bone gap of $39.8 \pm 7.7 \mathrm{~dB}$ to $22.18 \pm 7.9 \mathrm{~dB}$ after 6 months of septal cartilage tympanoplasty type 3 . Our results are comparable to Harvey et al. ${ }^{8}$ which reported a similar improvement in mean air bone gap of $23.8 \mathrm{~dB}$ after double cartilage tympanoplasty. Eleftherios A et al. ${ }^{1}$ also reported the mean air bone gap reducing from $40 \mathrm{~dB}$ to $19 \mathrm{~dB}$ in 6 months, follow up after type 3 chondrotympanoplasty.
Out of 20 patients who had undergone tympanoplasty with cortical mastoid bone after canal wall down mastoidectomy, the mean pre-operative air-bone gap was $39.04 \pm 8.06 \mathrm{~dB}$ and post-operative mean air-bone gap was $22.47 \pm 10.07$, suggesting significant improvement of hearing gain ( $\mathrm{p}=<0.001$ ). Among these patients, $40 \%$ had air-bone gap less than $20 \mathrm{~dB}$ and $65 \%$ had air-bone gap less than $30 \mathrm{~dB}$. The results of hearing improvement after canal wall down mastoidectomy is unpredictable. According to Lesinkas $\mathrm{E}$ and Vainutiene $\mathrm{V} .{ }^{9}$ none of the patients had hearing improvement after canal wall mastoidectomy. Moustafa HM and Khalifa MA. ${ }^{10}$ reported air bone gap less than $30 \mathrm{~dB}$ in less than $10 \%$ of the patients. In another study by Shrestha BL et al. 11 73.7\% of patients had air-bone gap closure within $30 \mathrm{~dB}$ and $60.5 \%$ had ABG closure within 20dB. 
In our study, only 2(4.8\%) patients had recurrence at 6 months followup. Ajaluoueyan. ${ }^{12}$ had reported recurrence rate of $7 \%$ after 10 years. The most common cause of recurrence is incomplete lowering of facial ridge. The recurrence rate of canal wall up technique ranges from $12 \%$ to $45 \%{ }^{1,13}$ Our study also agrees with the fact that canal wall down mastoidectomy has less chance of recurrence.

Atticoantral retraction of graft after tympanoplasty occurred in $1(2.4 \%)$ patient who had undergone tympanoplasty with cortical mastoid bone. Our results are better than Kim JH et al. ${ }^{14}$ where retraction rate was $18 \%$.

Graft resorption was seen in 2 patients who underwent septal cartilage tympanoplasty. This is almost similar to study by Rafael A and Ramfrez C. ${ }^{7}$ where 1 patient out of 32 cases had graft resorption. Cartilage could lose bulk over time with subsequent retraction. Our study showed that septal cartilage too can undergo resorption over time.

Three $(7.1 \%)$ patients had graft displacement, Sayed RH.15 also reported displacement in 2 patients out of 31 patients. Graft extrusion was not reported in our study. This is clearly the result of using non-infected autologous graft.

\section{CONCLUSIONS}

Canal wall down mastoidectomy has better disease clearance than canal wall up mastoidectomy surgery. There is significant improvement in hearing after the tympanoplasty using both septal cartilage and cortical mastoid bone grafts. However, cartilage graft has more chance of resorption. There is no significant difference between the septal cartilage and cortical mastoid bone in terms of hearing improvement. The present study shows cortical mastoid bone and septal cartilage are good autografts for tympanoplasty type 3 and they are good alternatives of synthetic grafts in terms of affordability and availability.

\section{REFERENCES}

1. Eleftherios AF, Thomas PN, Dimitrios CK, et al. Chondrotympanoplasty: a modified technique of cartilage graft tympanoplasty. Med SciMonit 2003;9(2):CR 73-78.

2. Sheikh AA. Myringoplasty by homologous temporal fascia. Indian J Otol 2001;7(2):71-74.
3. Cura O, Kriazli T, Oztop F. Can homograft ossicles still be used in ossiculoplasty? Rev Laryngol Otol Rhinol (Bord). 2000;121(2):87-90.

4. Jongkees LBW. On reoperation on patients treated by reconstructive middle ear surgery. Practicaotorhinolaryngologica. 1957;19:532-548.

5. Nicholas JF. Scott Brown's Otolaryngology: Reconstruction of ear. $6^{\text {th }}$ edition. Oxford: Butterworth Heinemann International Editions; 1997.

6. Jancen C. Cartilage tympanoplasty. Laryngoscope. 1963;73:1288-1302.

7. Rafael A, Ramfrez C. Tympanoplasty-Nasal cartilage homografts. Arch Otolaryngol 1981;107:608-609.

8. Harvey, Stevens A, Lin, et al. Double cartilage block ossiculoplasty in chronic ear surgery. Laryngoscope. 1999;109(6):911-914.

9. Lesinkas E, Vainutiene V. Closed tympanoplasty in middle ear cholesteatoma surgery. Medicinia 2004;40(9):856-859.

10. Moustafa HM, Khalifa MA. Tympano-CartilagoStapediopexy: a method to improve hearing in open technique tympanoplasty.

J Laryngol Otol 1990;104:942-944.

11. Shrestha BL, Bhusal CL, Bhattarai H. Comparision of preand post-operative hearing results in canal wall down mastoidectomy with type III tympanoplasty. J Nepal Med Assoc 47(172):224-227.

12. Ajalloueyan M. Experience with surgical management of cholesteatomas. Arch otolaryngol head and neck surg 2006;132(9):931-933.

13. Harvey Stevens A, Lin, et al. Double cartilage block ossiculoplasty in chronic ear surgery. Laryngoscope. 1999;109(6):911-914.

14. Kim JH, Choi SH, Chung JW. Clinical results of atticoantrotomy with attic reconstruction or attic obliteration for patients with an attic cholesteatoma. ClinExpOtorhinolaryngol. 2009;2(1):39-43.

15. Sayed RH. One stage reconstruction in the management of extensive cholesteatoma. Indian J Otol 2002;8(1):9-16. 